\title{
Mental health, anthropometry and blood pressure among adolescents living in slums of Nashik, India
}

\author{
SUSHAMA A. KHOPKAR ${ }^{1}$, SUVI M. VIRTANEN ${ }^{2,3}$ and SANGITA KULATHINAL ${ }^{*}$ \\ ${ }^{1}$ Department of Statistics, H.P.T. Arts and R.Y.K.Sc. College, Nashik 422005 , India \\ ${ }^{2}$ Unit of Nutrition, Department of Lifestyle and Participation, National Institute for Health and Welfare, Helsinki, \\ Finland, School of Health Sciences, University of Tampere, Tampere, Finland \\ ${ }^{3}$ Research Center for Child Health, Tampere University and University Hospital, and the Science Center of Pirkanmaa \\ Hospital District, Tampere, Finland \\ ${ }^{4}$ Department of Mathematics and Statistics, University of Helsinki, Fl-00014, Finland
}

\begin{abstract}
Background: Both hypertension and depression are common disorders and obesity is on the rise in low and middle-income countries. Because early life changes may prove to be a precursor to the development of diseases in adult, assessing the mental and physical health of younger population is crucial. This study aimed to determine the association between blood pressure, mental health and anthropometric status of adolescents from urban slums in Nashik, India.

Methods: A cross-sectional observational study was conducted among eligible adolescents during November 2010 and April 2011 in two randomly selected slums of Nashik, Maharashtra, India. A total of 545 adolescents were selected from 276 households. Data on socio-demographic indicators, anthropometry, blood pressure, mental wellbeing, and addictions were collected using pretested structured questionnaires by house visits. Mental wellbeing was examined using the General Health Questionnaire with 12 items (GHQ-12). A higher score indicates more-optimal mental wellbeing. Linear mixed effects models were used to analyse the data.

Results: Girls had better mental wellbeing scores than boys. Adolescents with low mental wellbeing score had higher percentage of stunting (22\%) compared to high scores. The factors associated significantly with systolic blood pressure (SBP) were age, mid mental wellbeing score, stunting, and thinness. For diastolic blood pressure (DBP), sex, high mental wellbeing score, and father's education were, in addition, also significant. When moving from the low to mid mental wellbeing score, SBP and DBP decreased and the same was observed for high score. The prevalence of prehypertension was $20 \%$.

Conclusion: The findings showed that the adolescents do run a higher risk of substance abuse, health-related problems and higher SBP and DBP if there is an evidence of distress. It brings into focus the importance of mental health management in adolescents.
\end{abstract}

Keywords: adolescents, blood pressure, mental wellbeing, nutritional status, slums, India

\section{Introduction}

Depression is a common illness worldwide, with an estimated 350 million people of all ages suffering from it (WHO, 2012). The burden of depression and other mental health conditions is on the rise globally and is a leading cause of disability (WHO, 2012). Depression results from a complex interaction of social, psychological and biological factors. It is known to have association with physical health. For instance, hypertension and obesity can lead to depression and vice versa (WHO, 2012; Stein et al., 2014). Among adolescents, depression is associated with poor health and behavioural outcomes, including higher risks of substance abuse, unsafe sexual practices, and violence (Saluja et al., 2004) and lower achievement on tests, lower teacher-rated grades, and poorer peer relationships (Roeser et al., 1998). Unfavourable living conditions of urban slums make them even more vulnerable, and may further increase the risk of substance abuse, adversely affect their general and mental health, and accelerate onset of chronic diseases such as high blood pressure and diabetes. These early life changes may prove to be a precursor to the development of diseases in adult life. Onset of depression before the age of 21 years has been of particular concern because of higher rates of recurrence, and higher overall rates of comorbid disorders, including substance abuse (Greden, 2001).

There have been a few studies exploring the interaction between mental and physical health

Correspondence: sangita.kulathinal@helsinki.fi 
among adolescents. Association between mental health and hypertension has been observed in general population (Stein et al., 2014) and obesity among adolescents in the United States (Kiessling et al., 2008; Tevie \& Shaya, 2015). Both obesity and hypertension have shown to increase the odds of poor mental health in a representative United States population of children and adolescents (Tevie \& Shaya, 2015). Hypertension can have its origin in childhood and may go undetected unless specifically looked for during this period (Aggarwal et al., 1982). Although blood pressure normally increases with growth and development, children with higher levels of blood pressure tend either to maintain that position as they mature or progress to higher levels of blood pressure in adulthood in comparison to their peer group (Luepker et al., 1999). Data from diverse populations show that the tracking of blood pressure from childhood into adulthood is very strong (Chen \& Wang, 2008). There is a general lack of literature on the association between mental health and hypertension among adolescents who are not overweight or obese, and specifically growing up in unfavourable living conditions.

A number of community-based studies have demonstrated that there is a strong positive relationship between anthropometric measurements, especially bodyweight, and blood pressure in adolescents (Muntner et al., 2004; Paradis et al., 2004; Kelishadi et al., 2006; Raj et al., 2007). Obesity is recognised as an important risk factor for cardiovascular disease. The prevalence of obesity is increasing in both developed and developing countries (Delpeuch \& Maire, 1997). Body mass index (BMI) is positively correlated with blood pressure even in lean or non-obese populations (Kaufman et al., 1997; He et al., 2000).

As a motivating example, we examined the association between blood pressure, mental health and anthropometric status (stunting and thinness) among adolescents using a sample from a study conducted in two slums of Nashik city in India. Mental wellbeing is a general term used in this article and is characterised by the score derived using the questions concentrated on symptoms related to potential depression and anxiety, self-esteem, stress, and coping.

\section{Material and Methods}

\section{Study area}

The study was conducted as a cross-sectional survey in two slums in Nashik, located on the banks of Godavari River in the state of Maharashtra, Western India. Nashik is a fast-growing largely industrial city of 1.5 million inhabitants, and situated less than 200 kilometres from Mumbai. Nashik urban agglomeration is the fourth largest in Maharashtra, and according to the census $2011,12.77 \%$ of the city population reside in the slums (Census of India, 2011).

\section{Study subjects and sampling}

The present study was conducted during November 2010 and April 2011 in two randomly selected slums of Nashik, Maharashtra, India. The target sample size was 500 adolescents in the age group of 10 to 19 years residing in the selected slums. The sample size was determined based on the main purpose of the study, which was to describe the socio-demographic and health profile of adolescents of urban slums, and the limited budget available for data collection. For this purpose, households with eligible adolescents and which gave written consent to participate in the study were recruited. A total of 545 adolescents were selected from 276 households. Data on socio-demographic indicators, adolescents' anthropometry, blood pressure, mental wellbeing, and addictions were collected using pretested structured questionnaires by house visits.

\section{Blood pressure}

Blood pressure (BP) measurements were taken by a trained team in a quiet room in the presence of a parent or a legal guardian and special care was taken to ensure that the subject was calm. Subjects were advised to avoid stimulating beverages like tea or coffee before the BP measurements. They were asked to rest for 10 minutes before the measurements of blood pressure. Two measurements were taken five minutes apart, with the subject in a supine position with both arms stretched comfortably and naturally using a new aneroid sphygmomanometer with a certified accuracy of $\pm 2 \mathrm{mmHg}$. The cuff 
size used was appropriate to the child's right arm according to recommendations by the National High Blood Pressure Education Program Working Group on High Blood Pressure in Children and Adolescents (2004). The average of two systolic blood pressure (SBP) and two diastolic blood pressure (DBP) measurements were used for the analysis.

Blood pressure percentiles for given sex, age (between 10 and 17 years) and height were computed using the steps given in Appendix B and regression parameters given in Table B1 (National High Blood Pressure Education Program Working Group on High Blood Pressure in Children and Adolescents, 2004). If a subject had both systolic as well as diastolic blood pressure percentiles for sex, age and height below 90 then he/she was classified as normotensive. If either of the blood pressure percentiles were above 95 then he/she was classified as hypertensive, and in other cases prehypertensive. A subject with SBP of $120 \mathrm{~mm} \mathrm{Hg}$ or above, or with DBP $80 \mathrm{~mm} \mathrm{Hg}$ or above was classified as prehypertensive even if the percentiles were below 90. For 18-year-old subjects, the standard definition of hypertension for adults was used. A subject was prehypertensive if SBP was at least $120 \mathrm{~mm} \mathrm{Hg}$ but below $140 \mathrm{~mm} \mathrm{Hg}$, or DBP was at least $80 \mathrm{~mm} \mathrm{Hg}$ but below $90 \mathrm{~mm} \mathrm{Hg}$, and hypertensive if SBP was $140 \mathrm{~mm} \mathrm{Hg}$ or above, or DBP was $90 \mathrm{~mm} \mathrm{Hg}$ or above. All the others were classified as normotensive.

\section{Mental wellbeing}

Mental wellbeing was examined using the General Health Questionnaire with 12 items (GHQ-12) with slight reformulation to suit the study subjects. GHQ is widely used as a screening instrument to identify psychological distress. The questions concentrated on symptoms related to potential depression and anxiety, self-esteem, stress, and coping. Each item response were in 4-point scoring system ranging from better than normal option, a same as usual and a worse than usual to a much worse than usual option. The responses were grouped into two categories: 1 (better than normal option) and o (other options), and then added up to derive a total score. The total ranged from 0 to 12; the higher the score, the better the adolescent's mental wellbeing. Similar binary scoring has been used in other studies (Ram et al., 2014). Since there is no threshold available for such binary scoring, we classified each subject, using the tertile, into one of the three categories: (i) low: score less than or equal to 7; (ii) mid: score between 8 and 10, and (iii) high: score 11 or 12 .

\section{Anthropometric measurements}

Data on height and weight were collected in the present study. Height (in $\mathrm{cm}$ ) was measured using a simple non-elastic measurement tape to the nearest integer. Weight (in $\mathrm{kg}$ ) was recorded using a new bathroom scale (brand Libra, Model no. 770) to the nearest integer. Two readings each were taken for height and weight and the average was used for analyses here. We refer to (Khopkar et al., 2014) for more details of anthropometric measurements.

\section{Family history of high blood pressure and parent's education}

A family history of high blood pressure is known to be a strong risk factor of hypertension. The children of mothers with high education tend to have lower blood pressure (Berg et al., 2013). We tested this hypothesis among the study subjects. The survey questionnaire included two questions on the family history of high blood pressure. If either of the parents was known to have high blood pressure then the family history of high blood pressure was coded as yes, and otherwise coded as no. We included both mother's and father's education in the analysis. The questionnaire included questions: "What is your mother's education level?" and "What is your father's education level?" These were used to obtain parents' education levels. The education levels were grouped into two categories: i) primary or no education, and ii) secondary or higher education, for the analysis purpose here.

\section{Addiction and health-related variables}

An individual was classified as using tobacco in any form currently if there was at least one positive answer to the question "Do you currently use any substances? (smoke, chew tobacco, gutka)". Similarly, current use of alcohol was defined. The questionnaire included questions on health-related 
problems. Data on experience of neck and back pain, headache, sleep and energy, sadness, problems with interpersonal activities (personal relationship, participation in the community, dealing with tension) were used to examine their association with the mental wellbeing scores. Such associations would be helpful in assessing the scoring system used here for mental wellbeing questionnaire.

\section{Ethical considerations}

The field study was approved by the Institutional Review Board of Tampere School of Health Sciences in 2010. The study was conducted in accordance with the ethical guidelines in the Helsinki Declaration of 1975, as revised in 2000.

\section{Data analysis}

The analysis was restricted to the age group $10-18$ years (boys $=257$, girls $=261$, total $=518$ ) since the growth curves from India were available up to the age of 18 years. Systolic and diastolic blood pressures were considered as dependent variables. On the other hand, mental wellbeing, thinness and stunting were considered as independent variables. Sex, parental education and family history of blood pressure are known to affect blood pressure and were also considered as independent variables. Other factors such as current use of tobacco and alcohol, health-related problems were assessed with respect to mental wellbeing.

Body mass index $\left(\mathrm{BMI}, \mathrm{kg} / \mathrm{m}^{2}\right)$ was defined as the ratio of weight (in $\mathrm{kg}$ ) to the square of height (in $\mathrm{m}$ ). Height-for-age and BMI-for-age $z$-scores were derived using the Indian reference population (Khadilkar et al., 2009). A subject was classified as stunted if the height-for-age score was below -2; thin if BMI-for-age score was below -2 and overweight if BMI-for-age score was above 1 (Khopkar et al., 2014). Height can be considered to be a measure of childhood nutrition and hence, height was also of interest for this age group. We refer to the classification based on BMI-for-age as nutritional status categorised into normal, thin and overweight. A combined category of prehypertension and hypertension was used for the analysis and was referred to as prehypertension.

Mental wellbeing was central to the analysis presented here and hence, all the variables including blood pressure were summarised according to the mental wellbeing score being in low-, midor high-range. The association between blood pressure and mental wellbeing was studied using generalised linear mixed effects model. Data on adolescents from the same household might be correlated and hence, regression models used for the analysis included a household-specific random effect. One of our main hypotheses of interest was to test whether mental wellbeing was associated with SBP and DBP. Two linear mixed effects models were fitted for each SBP and DBP. The first model included age, sex and mental wellbeing score. In the second model, other factors which were expected to associate with blood pressure were added. To account for the effect of age on height and BMI, stunting and thinness were used in the second model in place of height and BMI. All analyses were performed using the statistical computing environment $\mathrm{R}$ and regression analyses were implemented using the Glmer function from the package Ime4 of R (R Core Team, 2013; Bates et al., 2014).

\section{Results}

The categorical variables defined above were summarized by providing proportions and blood pressure was summarised by sample mean and standard deviation, for the three categories of mental wellbeing score (Table 1). It was observed that girls had higher score compared to boys. The nutritional status of 91\% of the adolescents was normal, and there were no differences observed in the mental wellbeing scores with regard to the nutritional status. However, the percentage of stunting was the highest (22\%) among those with the low-score. The prevalence of current use of tobacco $(20 \%)$ and alcohol (17\%) were the lowest among those with the high-score. The same applies to the health-related problems, higher the score lower the prevalence of problems. Adolescents with higher mental scores tended to have higher percentage of both parents with secondary or higher education (61\% mothers and $82 \%$ fathers) compared to lower score (46\% mothers and 59\% fathers). Mean systolic and diastolic blood pressure values decreased as the score increases and the prevalence of prehypertension was the lowest among 
those in the range of high mental wellbeing score. The overall prevalence of prehypertension among the study subjects was $20 \%$.

Table 1: Sample characteristics by mental wellbeing score

\begin{tabular}{|c|c|c|c|c|c|}
\hline \multirow[t]{2}{*}{ Variables } & & \multirow[t]{2}{*}{ Total $(\mathrm{N}=497)$} & \multicolumn{3}{|c|}{ Mental wellbeing score } \\
\hline & & & $\begin{array}{l}\text { Low } \quad(\leq 7) \\
(n=200)\end{array}$ & $\begin{array}{l}\text { Mid (8-10) } \\
(n=145)\end{array}$ & $\begin{array}{l}\text { High }(\geq 11) \\
(n=152)\end{array}$ \\
\hline Age (SD), years & & $13.8(2.4)$ & $14(2.5)$ & $14(2.4)$ & $13 \cdot 4(2 \cdot 3)$ \\
\hline Sex (\% boys) & & 50 & 53 & 50 & 47 \\
\hline Height (SD),cm & & $148.3(12.5)$ & $148(12.8)$ & $148.8(12.6)$ & $148.1(12.1)$ \\
\hline Stunting (\% stunted) & & 15 & 22 & 10 & 12 \\
\hline $\mathrm{BMI}(\mathrm{SD}), \mathrm{kg} / \mathrm{m}^{2}$ & & $16.6(2.8)$ & $16.7(2.6)$ & $16.7(2.7)$ & $16.4(3)$ \\
\hline \multirow[t]{3}{*}{ Nutritional status (\%) } & Normal & 91 & 90 & 91 & 90 \\
\hline & Overweight & 2 & 1 & 2 & 2 \\
\hline & Thin & 8 & 8 & 7 & 8 \\
\hline \multirow[t]{2}{*}{ Addiction } & $\begin{array}{l}\text { Currently using } \\
\text { tobacco }\end{array}$ & 27 & 30 & 32 & 20 \\
\hline & $\begin{array}{l}\text { Currently consuming } \\
\text { alcohol }\end{array}$ & 20 & 21 & 23 & 17 \\
\hline \multirow[t]{7}{*}{ Health-related problems } & $\begin{array}{l}\text { Neck and back pain, } \\
\text { headache }\end{array}$ & 79 & 93 & 79 & 62 \\
\hline & $\begin{array}{l}\text { Sleep and energy } \\
\text { related problem }\end{array}$ & 45 & 53 & 43 & 34 \\
\hline & Sadness & 15 & 17 & 17 & 12 \\
\hline & Interpersonal activities & 29 & 40 & 29 & 13 \\
\hline & Mother's education & 51 & 46 & 47 & 61 \\
\hline & Father's education & 68 & 59 & 67 & 82 \\
\hline & Family history of BP & 10 & 8 & 10 & 12 \\
\hline \multirow[t]{3}{*}{ Blood pressure } & $\mathrm{SBP}(\mathrm{SD}), \mathrm{mmHg}$ & $105.7(11.8)$ & $106(11.6)$ & $105.4(12.2)$ & $105.7(11.9)$ \\
\hline & $\mathrm{DBP}(\mathrm{SD}), \mathrm{mmHg}$ & $65(7.1)$ & $65.9(7.5)$ & $64.8(7.4)$ & $64.2(6.3)$ \\
\hline & Prehypertension (\%) & 20 & 20 & 22 & 19 \\
\hline
\end{tabular}

When mental wellbeing score was used as an independent variable in a regression model, adjusted for age and sex, with systolic blood pressure as a dependent variable (Model 1, Table 2), no significant association was observed. But when diastolic blood pressure was used (Model 3, Table 2), there was significant decrease in DBP with increase in the score range, and sex was also significant with girls having higher DBP than boys. Model 2 and 4 included other factors which might affect blood pressure. The factors associated significantly with SBP (Model 2, Table 2) were age, mid mental wellbeing score $(8,9$, or 10$)$, stunting, and thinness. For DBP (Model 4, Table 2), sex, high mental wellbeing score, and father's education were, in addition, also significant. 
Table 2: Regression coefficients and their $90 \%$ confidence intervals when systolic and diastolic blood pressure are regressed over mental wellbeing scores and other known risk factors

\begin{tabular}{|c|c|c|c|c|c|}
\hline \multirow[t]{2}{*}{ Variable } & & \multicolumn{2}{|c|}{ Systolic blood pressure } & \multicolumn{2}{|c|}{ Diastolic blood pressure } \\
\hline & & Model 1 & Model 2 & Model 3 & Model 4 \\
\hline Intercept & & $\begin{array}{l}74.32^{* * *} \\
(69.56,79.07)\end{array}$ & $\begin{array}{l}77.08^{* * *} \\
(72.2,81.97)\end{array}$ & $\begin{array}{l}50.45^{* * *} \\
(47.46,53.44)\end{array}$ & $\begin{array}{l}50.86 * * * \\
(47.67,54.04)\end{array}$ \\
\hline Age (in years) & & $\begin{array}{l}2.28 * * * \\
(1.95,2.6)\end{array}$ & $\begin{array}{l}2.26 * * * \\
(1.95,2.57)\end{array}$ & $\begin{array}{l}1.05^{* * *} \\
(0.84,1.25)\end{array}$ & $\begin{array}{l}1.04^{* * *} \\
(0.84,1.625)\end{array}$ \\
\hline Sex (Ref. boys) & & $\begin{array}{l}-0.45 \\
(-2,1.1)\end{array}$ & $\begin{array}{l}-1.31 \\
(-2.8,0.18)\end{array}$ & $\begin{array}{l}1.73^{* *} \\
(0.76,2.7)\end{array}$ & $\begin{array}{l}1.41^{* *} \\
(0.44,2.38)\end{array}$ \\
\hline \multirow[t]{2}{*}{$\begin{array}{l}\text { Mental wellbeing score } \\
\text { (Ref. score } 7 \text { or below) }\end{array}$} & Score $(8,9$ or 10$)$ & $\begin{array}{l}-0.65 \\
(-2.58,1.28)\end{array}$ & $\begin{array}{l}-2.09^{*} \\
(-3.92,-0.26)\end{array}$ & $\begin{array}{l}-1.25^{*} \\
(-2.46,-0.04)\end{array}$ & $\begin{array}{l}-1.86^{* *} \\
(-3.05,-0.67)\end{array}$ \\
\hline & Score (11 or 12$)$ & $\begin{array}{l}1.14 \\
(-0.8,3.08)\end{array}$ & $\begin{array}{l}0.23 \\
(-1.64,2.09)\end{array}$ & $\begin{array}{l}-1.21 \\
(-2.42,0.01)\end{array}$ & $\begin{array}{l}-1.67^{*} \\
(-2.88,-0.46)\end{array}$ \\
\hline $\begin{array}{l}\text { Stunting } \\
\text { (Ref. not stunted) }\end{array}$ & & & $\begin{array}{l}-8.88 * * * \\
(-10.99,-6.77)\end{array}$ & & $\begin{array}{l}-2.63^{* * *} \\
(-4,-1.25)\end{array}$ \\
\hline \multirow[t]{2}{*}{$\begin{array}{l}\text { BMI-for-age } \\
\text { (Ref. normal) }\end{array}$} & Overweight & & $\begin{array}{l}11.94^{* * *} \\
(6.13,17.75)\end{array}$ & & $\begin{array}{l}5.86 * * \\
(2.07,9.65)\end{array}$ \\
\hline & Thin & & $\begin{array}{l}-5.42^{* *} \\
(-8.17,-2.68)\end{array}$ & & $\begin{array}{l}-3.45^{* * *} \\
(-5.24,-1.66)\end{array}$ \\
\hline $\begin{array}{l}\text { Family history of BP } \\
\text { (Ref. no history) }\end{array}$ & & & $\begin{array}{l}-0.64 \\
(-3.34,2.06)\end{array}$ & & $\begin{array}{l}-1.00 \\
(-2.74,0.74)\end{array}$ \\
\hline $\begin{array}{l}\text { Mother's education } \\
\text { (Ref. primary or no } \\
\text { education) }\end{array}$ & & & $\begin{array}{l}-1.14 \\
(-2.81,0.53)\end{array}$ & & $\begin{array}{l}-0.52 \\
(-1.6,0.56)\end{array}$ \\
\hline $\begin{array}{l}\text { Father's education } \\
\text { (Ref. primary or no } \\
\text { education) }\end{array}$ & & & $\begin{array}{l}1.14 \\
(-0.67,2.94)\end{array}$ & & $\begin{array}{l}1.48^{*} \\
(0.31,2.65)\end{array}$ \\
\hline
\end{tabular}

Significance code: $0 * * * 0.001,{ }^{* *} 0.01,{ }^{*} 0.1 ;$ Ref. Reference category used in the model

SBP and DBP increased when moving from normal to overweight category while decreased when moving to thin category. Stunted adolescents tended to have lower SBP and DBP compared to nonstunted. When moving from the low mental wellbeing score (7 or below) to mid score (8, 9, or 10), SBP and DBP decreased and the same was observed for high score. DBP was higher when moving from primary or no education for father to secondary or higher education.

\section{Discussion}

India has a large population of adolescents (10-19 years of age, 21\%) and also of slum dwellers in urban areas (15\% of total urban population of India) (Census of India, 2011; Upinder, 2013). Maharashtra has the highest slum population as a proportion of urban population (27.3\%) in India (Upinder, 2013). Generally the slum population is economically poor and also hierarchically positioned low in a caste society. About two thirds of the study population was below the poverty line of the state of Maharashtra (below per capita income of Indian Rupee 961 or US\$ 15). To the best of our knowledge, this is also the first study where the association between mental wellbeing and blood pressure of underprivileged adolescents of India has been examined. This study detects that the known factors of age, height and BMI, but not family history, influence blood pressure among adolescents. This may be partly explained by the low proportion of family history of high blood pressure. It also brings into focus that in a situation where the majority of study subjects were classified as normal with respect to BMI-for-age and $85 \%$ were not 
stunted, reduction in distress among adolescents would help maintaining SBP and DBP at normal levels. An analysis of normal and non-stunted adolescents revealed that mid- and high- mental wellbeing scores had significantly lower DBP compared to low-score (data not shown). And mother's education also decreased DBP.

A recent study on adolescents from US brings into focus the maintenance of a healthy body mass index and control of hypertension in improving the mental health of younger populations in the US (Tevie \& Shaya, 2015). Both high blood pressure and depression are very common disorders (Murray \& Lopez, 2013). The relationship between high BP and depression is thought to be bidirectional by many researchers (Tevie \& Shaya, 2015). However, it is natural to expect that the mental anxiety is likely to increase BP, first temporarily and it may later on develop to permanent hypertension, but it is not very clear how the relationship works the other way around.

Throughout adulthood, blood pressure is strongly and directly related to vascular as well as overall mortality (Lewington et al., 2002). Early diagnosis, treatment, and follow-up of the hypertensive cases and preventive methods may decrease future morbidity and mortality. There is a wide variation in the prevalence of hypertension in children in India ranging from a high of $11 \%$ to as low as $0.46 \%$ (Mohan et al., 2004; Singh et al., 2006; Kumar et al., 2012). The prevalence of prehypertension (hypertension and prehypertension combined) among the study population is comparable to that observed in developed countries, e.g. USA (18.9\%) and Switzerland (24.7\%) (McNiece et al., 2007; Chiolero et al., 2007).

A community-based cross-sectional study of adolescents aged 10-19 years from an urban slum of Chetla, Kolkata, India reported the prevalence of hypertension as $2.9 \%$ with the highest prevalence (5.6\%) observed for the age group 18-19 years (Saha et al., 2008). An epidemiological study of blood pressure among school children (5-14 Years) in Delhi showed that SBP and DBP increased with age in both sexes (Chadha et al., 1999). The cut-off points for high blood pressure were based on the average SBP and/or DBP values of $95^{\text {th }}$ percentile or greater for each age. In the age group 10-14 years, the values for SBP and DBP ranged from $72 \mathrm{~mm} \mathrm{Hg}$ to $160 \mathrm{~mm} \mathrm{Hg}$ and from $46 \mathrm{~mm} \mathrm{Hg}$ to $120 \mathrm{~mm} \mathrm{Hg}$, for boys and girls, respectively. There was no significant difference in the prevalence of hypertension (systolic, diastolic or both) on the basis of gender. Anthropometric variables like height, weight and body mass index showed positive correlations with systolic as well as diastolic blood pressure. A family history of hypertension in one or both the parents was present in one-fifth of the children with high blood pressure (Chadha et al., 1999).

The present study had several limitations which are worth mentioning. It was a small study with only two slums, and had two measurements of blood pressure as against the recommendation of three measurements. Comparisons of adolescents living in slums and non-slums with respect to the mental wellbeing and other socio-demographic factors would be of interest and a study with this aim need to be planned. The data on salt intake and physical activities were homogeneous and hence, the association between blood pressure and these variables could not be studied. In spite of these limitations, the study point towards an emerging public health issue of hypertension among adolescents and brings out the determinants that might require attention.

In conclusion, the adolescents do run a higher risk of substance abuse, health-related problems and higher SBP and DBP if there is an evidence of distress. These findings have important implications for mental health management in adolescents.

\section{Acknowledgements}

The study was supported by a scholarship of The International Postgraduate Program in Epidemiology and Public Health (IPPE) at the School of Health Sciences, University of Tampere, Finland. The authors would like to thank Minna Säävälä, Väestöliitto, Helsinki, Finland, for helpful discussion and comments on the paper.

\section{References}

Aggarwal, R., Mendoware, S.L., Bhandari, B. \& Garg, O.P. (1982) Prevalence of hypertension in 
apparently healthy school children. Indian Pediatrics 19, 779-789.

Bates, D., Maechler, M., Bolker, B., Walker, S. Ime (2014) Linear mixed-effects models using Eigen and S4. R package version 1.1-7, 2014, (URL: http://CRAN.R-project.org/package=Ime4).

Berg, G.V.D., Eijsden, M.V., Galindo-Garre, F., Vrijkotte, T.G.M. \& Gemke, R.J.B.J. (2013) Explaining socioeconomic inequalities in childhood blood pressure and prehypertension: The ABCD study. Hypertension 61, 35-41.

Census of India (2011) Single year age data Table C13. (available from http://www.censusindia.gov.in/2011census/Age_level_data/Age_level_data.html).

Chadha, S.L., Tandon, R., Shekhawat, S. \& Gopinath, N. (1999) An epidemiological study of blood pressure in school children (5-14 years) in Delhi. Indian Heart Journal 51, 178-182.

Chen, X. \& Wang, Y. (2008) Tracking of blood pressure from childhood to adulthood: a systematic review and meta-regression analysis. Circulation 117, 3171-3180.

Chiolero, A., Paccaud, F. \& Bovet, P. (2007) Pre-hypertension and hypertension among adolescents of Switzerland. Journal of Pediatrics 151: e24-e25.

Delpeuch, F. \& Maire, B. (1997) Obesity and developing countries of the south. Med Trop (Mars). 1997; 57, 380-388.

Greden, J. (2001) The burden of recurrent depression: causes, consequences, and future prospects. Journal of Clinical Psychiatry 62, 5-9.

He, Q., Ding, Z.Y., Fong, D.Y-T. \& Karlberg, J. (2000) Blood pressure is associated with body mass index in both normal and obese children. Hypertension 36, 165-170.

Kaufman, J.S., Asuzu, M.C., Mufunda, J., Forrester, T., Wilks, R., Luke, A., Long, A.E. \& Cooper, R.S. (1997) Relationship between blood pressure and body mass index in lean populations. Hypertension 30, 1511-1516.

Kelishadi, R., Ardalan, G., Gheiratmand, R., Majdzadeh, R., Delavari, A., Heshmat, R., Gouya, M.M., Razaghi, E.M., Motaghian, M., Mokhtari, M.R., Barekati, H., Arabi, M.S. CAPSIAN Study Group (2006) Blood pressure and its influencing factors in a national representative sample of Iranian children and adolescents: the CASPIAN Study. European Journal of Cardiovascular and Preventive Rehabilitation 13, 956-963.

Khadilkar, V.V., Khadilkar, A.V., Cole, T.J. \& Sayyad, M.G. (2009) Cross-sectional growth curves for height, weight and body mass index for affluent Indian children. Indian Pediatrics 46, 477-489.

Khopkar, S.A., Virtanen, S.M. \& Kulathinal, S. (2014) Anthropometric characteristics of underprivileged adolescents: a study from urban slums of India. Journal of Anthropology. Article ID 197048. doi:10.1155/2014/197048.

Kiessling, S.G., McClanahan, K.K. \& Omar, H.A. (2008) Obesity, hypertension, and mental health evaluation in adolescents: A comprehensive approach. International Journal of Adolescent Medicine and Health 20, 5-15.

Kumar, J., Deshmukh, P.R. \& Garg, B.S. (2012) Prevalence and correlates of sustained hypertension in adolescents of rural Wardha, Central India. Indian Journal of Pediatrics 79, 1206-1212.

Lewington, S., Clarke, R., Qizilbash, N., Peto, R. \& Collins, R. (2002) Prospective Studies Collaboration. Age specific relevance of usual blood pressure to vascular mortality: a meta-analysis of individual data for one million adults in 61 prospective studies. Lancet 360, 1903-1913.

Luepker, R.V., Jacobs, D.R., Prineas, R.J. \& Sinaiko, A.R. (1999) Secular trends of blood pressure and body size in a multi-ethnic adolescent population: 1986 to 1996. Journal of Pediatrics 134, 668674 .

McNiece, K.L., Poffenbarger, T.S., Turner, J.L., Franco, K.D., Sorof, J.M. \& Portman, R.J. (2007) Prevalence of hypertension and pre-hypertension among adolescents. Journal of Pediatrics 150, 640-644.

Mohan, B., Kumar, N., Aslam, N., Rangbulla, A., Kumbkarni, S., Sood, N.K. \& Wander, G.S. (2004) Prevalence of sustained hypertension and obesity in urban and rural school going children in Ludhiana. Indian Heart Journal 56, 310-314.

Muntner, P., He, J., Cutler, J.A., Wildman, R.P. \& Whelton, P.K. (2004) Trends in blood pressure among children and adolescents. JAMA 291, 2107-2113. 
Murray, C. \& Lopez, A. (2013) Global Health Measuring the Global Burden of Disease. New England Journal of Medicine 369, 448-557.

Paradis, G., Lambert, M., O’Loughlin, J., Lavallée, C., Aubin, J., Delvin, E. \& Hanley, J.A. (2004) Blood pressure and adiposity in children and adolescents. Circulation 110, 1832-1838.

$\mathrm{R}$ Core Team, "R: A language and environment for statistical computing. R Foundation for Statistical Computing," Vienna, 2013, Austria. (URL: http://www.R-project.org/).

Raj, M., Sundaram, K.R., Paul, M., Deepa, A.S. \& Kumar, R.K. (2007) Obesity in Indian children: time trends and relationship with hypertension. National Medical Journal of India 20, 288-293.

Ram, U., Strohschein, L. \& Gaur, K. (2014) Gender socialization: Differences between male and female youth in India and associations with mental health. International Journal of Population Research Article ID 357145. doi 10.1155/2014/357145.

Roeser, R., Eccles, J. \& Strobel, K. (1998) Linking the study of schooling and mental health: selected issues and empirical illustrations at the level of the individual. Educational Psychologist 33, 153176.

Saha, I., Paul, B. \& Dasgupta, A. (2008) Prevalence of hypertension and variation of blood pressure with age among adolescents in Chelta, India. Tanzania Journal of Health Research 10, 108-111.

Saluja, G., lachan, R., Scheidt, P.C., Overpeck, M.D., Sun, W. \& Giedd, J.N. (2004) Prevalence of and risk factors for depressive symptoms among young adolescents. Achieves of Pediatrics and Adolescent Medicine 158, 760-765.

Singh, A.K., Maheshwari, A., Sharma, N. \& Anand, K. (2006) Lifestyle associated risk factors in adolescents. Indian Journal of Pediatrics 73, 901-906.

Stein, D.J., Aguilar-Gaxiola, S., Alonso, J., Bruffaerts, R., de Jonge, P., Liu, Z., Miguel Caldas-de-Almeida, J., O'Neill, S., Viana, M.C., Al-Hamzawi, A.O., Angermeyer, M.C., Benjet, C., de Graaf, R., Ferry, F., Kovess-Masfety, V., Levinson, D., de Girolamo, G., Florescu, S., Hu, C., Kawakami, N., Maria Haro, J., Piazza, M., Posada-Villa, J., Wojtyniak, B.J., Xavier, M., Lim, C.C., Kessler, R.C., Scott, K.M. (2014) Associations between mental disorders and subsequent onset of hypertension. General Hospital Psychiatry 36, 142-149.

Tevie, J. \& Shaya, F.T. (2015) Association between mental health and comorbid obesity and hypertension among children and adolescents in the US. European Child Adolescent Psychiatry 24, 497-502.

National High Blood Pressure Education Program Working Group on High Blood Pressure in Children and Adolescents (2004) The fourth report on the diagnosis, evaluation, and treatment of high blood pressure in children and adolescent. Pediatrics 114 (Suppl $4^{\text {th }}$ Report), 555-576.

Upinder, S. (2013) Slum population in India: Extent and policy response. International Journal of Research in Business and Social Science 2, 47-56.

World Health Organisation (WHO) Depression, Fact sheet $\mathrm{N}^{\circ} 369$ October 2012. URL: http://www.who.int/mediacentre/factsheets/fs369/en/ 